\title{
VAI TRÒ CỦA HỘI CHÚNG MAY - THURNER TRONG BỆNH LÝ HUYÊTT KHỐI TĨNH MẠCH SÂU CHI DƯỚI
}

\section{TÓM TẮT}

Nhóm I: Hồi cứu hồ sơ và khảo sát lại $\mathrm{CT}$ Scan, chúng tôi ghi nhận 30 trường hợp huyết khối tĩnh mạch sâu chi dưới (HKTMSCD) được can thiệp lấy huyết khối bằng Fogarty, trong đó có 9/30 trường hợp được xác định $\mathrm{HC}$ May Thurner. Tuổi trung bình là 44,4 , tỷ lệ nam/nữ là $1 / 8$. Tỷ lệ tái huyết khối sớm cao là $89 \%$ và điểm số VCSS (Venous Clinical Severity Score) trung bình là 7,625. Can thiệp sửa chữa tổn thương giải phẫu của HC May-Thurner chỉ thành công về mặt kỹ thuật ở 01 trường hợp. Nhóm II: Can thiệp điều trị lấy huyết khối cho 60 trường hợp, chụp khảo sát trong mổ kết hợp với hình ảnh $\mathrm{CT}$ cản quang thì tĩnh mạch, ghi nhận được 37/60 $(61,6 \%)$ trường hợp có $\mathrm{HC}$ May-Thurner. Can thiệp sửa chữa tổn thương bằng nong bóng - stent thành công về mặt kỹ thuật là 35/37 (94,6\%). Tỷ lệ tái huyết khối sớm cải thiện hơn rõ so với nhóm I 21,6\% (8/37) và điểm số VCSS trung bình cũng cải thiện hơn là 5,025 . HKTMSCD do $\mathrm{HC}$ May-Thurner là bệnh cảnh thường gặp trên lâm sàng. Cần lưu ý hướng đến chẩn đoán này khi người bệnh có biểu hiện sưng phù 1 bên chân Trái. Phương tiện chẩn đoán xác định dựa vào hình ảnh học với vai trò của chụp CT Venography. Điều trị theo phác đồ hiện nay là lấy huyết khối với tiêu sợi huyết tại chỗ và sửa chữa thương tổn giải phẫu bằng nong bóng và stent.

Từ khóa: Huyết khối tĩnh mạch sâu chi dưới, hội chứng May-Thurner, thang điểm độ nặng lâm sàng tĩnh mạch.

\section{SUMMARY}

\section{THE ROLE OF MAY-THURNER SYNDROME IN DEEP VENOUS THROMBOSIS}

Group I: Among the 30 patients who underwent surgical thrombectomy by Fogarty balloon, we identified 9/30 (30\%) cases of May-
Lê Phi Long*, Nguyễn Hoài Nam**

Thurner syndrome. The mean age was 44.4. Male/female rate was $1 / 8$. The early rethrombosis rate was high as $89 \%$, and the mean VCSS score was 7.265. The success rate of endovenous interventional reconstruction was seen in only 1 case technically. Group II: Surgical thrombectomy and/or endovenous interventional reconstruction were performed in 60 cases. Fifty seven of them were acute proximal deep venous thrombosis and three of them were postthrombotic syndrome. The diagnosis of MayThurner syndrome was confirmed in $37 / 60(61.6 \%)$ cases by preoperative CT venography images and intraoperative contrast venography. Endovenous reconstruction by ballooning and stenting were successfully performed in 35/37 (94.6\%) cases. The early rethrombosis in this group was significantly lower than that in group I (21.6\% versus $89 \%)$ and the quality of life after treatment was also improved when comparing the VCSS score between the 2 group (5.025 versus 7.265). May-Thurner syndrome is considered as a common cause of deep venous thrombosis. This diagnosis should be confirmed, especially if the symptom is left leg swelling. The diagnosis is mainly based on the specific images of CT Scan venography. Current guideline for the treatment suggests catheter directed thrombolysis following by endovenous ballooning and stenting reconstruction.

Keywords: Deep venous thrombosis, MayThurner syndrome, Venous Clinical Severity Score.

\footnotetext{
* Khoa Lồng ngực - mạch máu, Bệnh viện Đại học Y Dược Hồ Chi Minh.

** Bộ môn phẫu thuật Tim mạch - Lồng ngục, Đại học Y Dược Hồ Chí Minh

Người chịu trách nhiệm khoa họ: Ths. Lê Phi Long

Ngày nhận bài: 01/05/2018 - Ngày Cho Phép Đăng: 20/05/2018

Phản Biện Khoa học: GS.TS. Bùi Đức Phú PGS.TS. Đặng Ngọc Hùng
} 


\section{I. ĐẶT VẤN ĐỀ}

Huyết khối tĩnh mạch sâu chi dưới là bệnh lý rất thường gặp, có liên quan đến nhiều bệnh lý nội ngoại khoa khác nhau. Theo thống kê trên 9 nghiên cứu dịch tễ tại Hoa Kỳ, tỷ lệ mắc bệnh mới hàng năm là $50,4 / 100.000$ người ${ }^{(5)}$. Bệnh có liên quan mật thiết đến rất nhiều các yếu tố nguy cơ. Việc tầm soát và kiểm soát các yếu tố nguy cơ, đồng thời đi sâu chẩn đoán nguyên nhân của HKTMSCD là rất quan trọng, giúp xác định phác đồ điều trị và phòng ngừa thích hợp, để mang lại kết quả điều trị tốt và giảm thiểu tái phát bệnh.

Hội chứng May-Thurner, hay còn gọi là $\mathrm{HC}$ Cockette theo các tác giả người Pháp, là một trong số các nguyên nhân đặc biệt gây ra HKTMSCD. Như đã biết, phác đồ điều trị HKTMSCD phụ thuộc rất nhiều vào việc đánh giá các yếu tố nguy cơ và xác định nguyên nhân gây bệnh. Do đó, chẩn đoán ra nguyên nhân này sẽ giúp BS lâm sàng lựa chọn được phác đồ điều trị và phòng ngừa phù hợp, tránh tái phát, giảm thiểu nguy cơ biến chứng thuyên tắc phổi và di chứng mạn tính là hội chứng hậu huyết khối.

Hiện nay, việc chẩn đoán HKTMSCD ở nước ta thường chỉ dừng lại ở mức xác định ra bệnh HKTMSCD. HC May-Thurner còn ít được chú ý nên ít có chẩn đoán hướng đến. Vì vậy, chúng tôi nhận thấy cần phải khảo sát truy tìm hội chứng này, để có hướng nghiên cứu tiếp tục sâu và rộng hơn.

\section{II. ĐỐI TƯợNG - PHƯƠNG PHÁP NGHIÊN CÚU}

Đối tượng nghiên cứu: các trường hợp HKTMSCD được can thiệp ngoại khoa bằng phẫu thuật lấy huyết khối

Thời gian: nhóm I từ tháng 01/2014 đến tháng $06 / 2016$, nhóm II từ $06 / 2016$ đến tháng $09 / 2017$

Thiết kế nghiên cúu: nhóm I: mô tả hồi cứu + cắt ngang, nhóm II: mô tả tiền cứu.

Phuơng pháp thục hiện: Nhóm I: hồi cứu hồ sơ, khảo sát phim chụp CT Scan, kết hợp với dữ kiện lâm sàng, tường trình phẫu thuật. Ghi nhận chẩn đoán HC May - Thurner phối hợp các đặc điểm lâm sàng khác. Ghi nhận tỷ lệ tái phát huyết khối sớm và đánh giá điểm VCSS.

Nhóm II: thu thập tất cả các trường hợp huyết khối tĩnh mạch sâu chi dưới, can thiệp ngoại khoa lấy huyết khối, kèm hoặc không kèm theo nong và stent tĩnh mạch, xác định chẩn đoán $\mathrm{HC}$ MayThurner, xác định tỷ lệ tái huyết khối sớm và đánh giá mức độ cải thiện lâm sàng thông qua bảng điểm VCSS.

\section{KẾT QUẢ}

\section{Mẫu khảo sát}

Ở nhóm I, hồi cứu từ tháng 01/2014 đến 06/2016, chúng tôi thu thập được 30 trường hợp HKTMSCD cấp tính, được can thiệp ngoại khoa lấy huyết khối bằng bóng Fogarty. Qua khảo sát lại hình ảnh chụp CT Scan có cản quang ở thì tĩnh mạch, dựng hình 3 chiều hệ thống TM chủ - chậu, chúng tôi chẩn đoán hồi cứu xác định được 09 trường hợp có $\mathrm{HC}$ May - Thurner.

Ở nhóm II, khảo sát hình ảnh Ct Scan cản quang chụp thì tĩnh mạch kết hợp với hình ảnh chụp tĩnh mạch cản quang trong mổ trên 60 trường hợp huyết khối tĩnh mạch sâu chi dưới được điều trị ngoại khoa, chúng tôi xác định chẩn đoán HC May-Thurner xuất hiện trong 37/60 trường hợp.

Như vậy, tần suất xuất hiện $\mathrm{HC}$ May Thurner trong nghiên cứu của chúng tôi là 46/90, chiếm tỷ lệ là $51,1 \%$.

\section{Độ tuổi - Giới tính}

Tỷ lệ nam / nữ là 23/67. Nữ chiếm tỷ lệ đa số là $74,4 \% \%$.

Độ tuổi trung bình của các trường hợp $\mathrm{HC}$ May - Thurner trong lô nghiên cứu này là 44,4 , cao nhất là 76 tuổi, thấp nhất là 26 tuổi.

\section{Đặc điểm lâm sàng - Yếu tố nguy co'}

Tất cả 90 trường hợp đều ghi nhận triệu chứng chính đến viện là sưng phù lan rộng ở một bên chân, từ bàn chân đến vùng đùi. Chúng tôi ghi nhận có 1 trường hợp có kèm theo biểu hiện dãn TM nông dưới da. Có 03 trường hợp có biểu hiện ở thể 
mạn tính trong $\mathrm{HC}$ hậu huyết khối: sung phù một bên chân Trái chân thường xuyên khi đứng lâu, kèm theo chàm và xạm da cẳng chân, 01 trường hợp có kèm theo loét loạn dưỡng. Không có trường hợp nào khai tức ngực hoặc khó thở để gợi ý triệu chứng của thuyên tắc phổi. Chúng tôi ghi nhận có 01 trường hợp ở thể cấp tính: sưng phù căng và đau nhiều, có dấu hiệu chèn ép khoang, làm lạnh tái vùng bàn chân, đe dọa chuyển sang tình trạng phlegmasia cerulea dolens.

Như đã trình bày ở mục trên, chúng tôi xác định được nguyên nhân gây bệnh là do HC MayThurner ở 46/90 trường hợp. Còn lại 44 trường hợp, tiếp tục khảo sát các yếu tố nguy cơ để hướng đến tìm nguyên nhân, chúng tôi ghi nhận 06 trường hợp có sử dụng thuốc ngừa thai đường uống, 02 trường hợp có $\mathrm{u}$ xơ tử cung to chèn ép vùng chậu, 03 trường hợp có bệnh lý tăng đông nguyên phát (gồm 2 trường hợp giảm Protein $\mathrm{S}$ và 01 trường hợp thiếu hụt antithrombin III). Không có trường hợp nào có liên quan đến các yếu tố về phẫu thuật (trong vòng 1 tuần), ung thư, chấn thương, hoặc các bệnh lý tăng đông khác. Bệnh sử gia đình cũng không ghi nhận có người cùng huyết thống mắc bệnh tương tự. Như vậy, còn lại 33 trường hợp không tìm thấy được nguyên nhân rõ ràng hoặc yếu tố nguy cơ.

\section{Đặc điểm hình ảnh học - CT Venography}

Đặc điểm chung của các trường hợp HC MayThurner trong lô nghiên cứu, trên hình ảnh CT Scan bơm cản quang chụp thì tĩnh mạch, là huyết khối lấp đầy lòng $\mathrm{TM}$, kéo dài từ $\mathrm{TM}$ khoeo lên đến $\mathrm{TM}$ đùi, lan rộng đến TM chậu ngoài, chậu chung. Huyết khối lan đến sát chỗ hợp lưu, cũng là vị trí bắt chéo với ĐM chậu chung Phải (Hình 1). Tại vị trí này, hình ảnh của $T M$ chậu gốc hoặc là bị hẹp, hoặc khó khảo sát thấy, khảo sát trên các phim cắt ngang. Trên hình ảnh cắt đứng dọc, có thể thấy rõ $\mathrm{TM}$ chậu chung nằm sát trước cột sống và xương cùng, bị chèn ép từ phía trước bởi ĐM chậu chung (Hình 2).

Qua CT Scan ngực, chúng tôi cũng ghi nhận có 8 trường hợp có huyết khối các nhánh nhỏ của ĐM phổi.

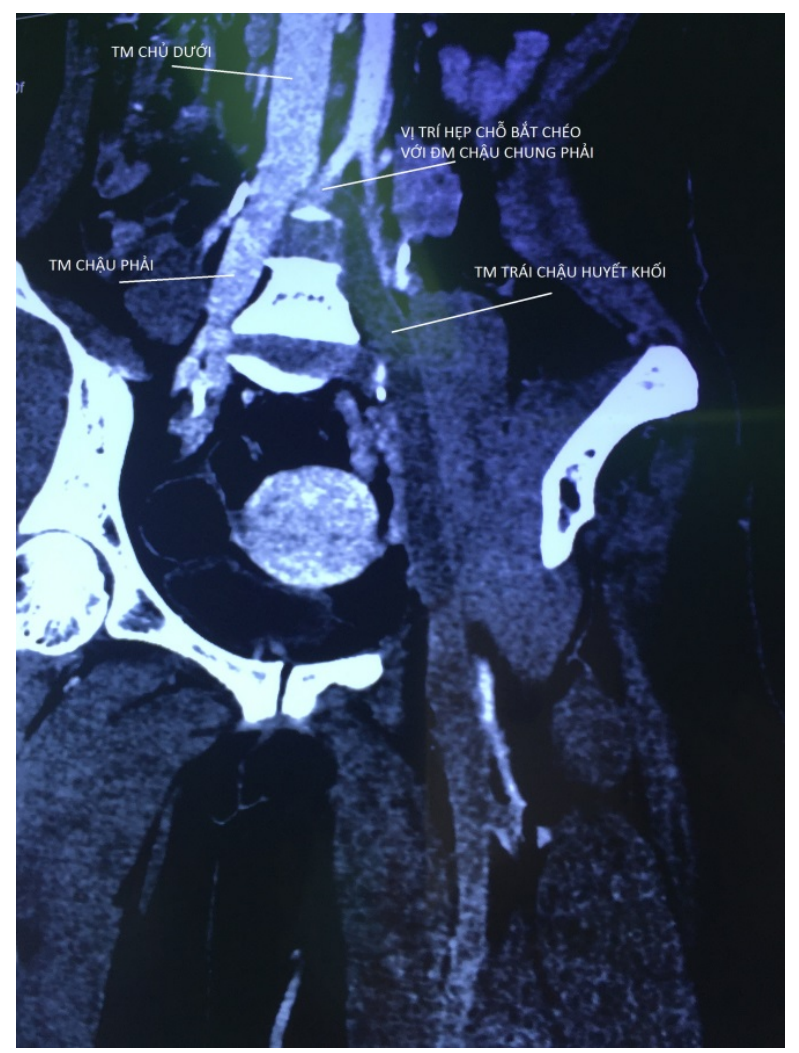

Hinh 1. Vị trí bắt chéo ĐM chậu

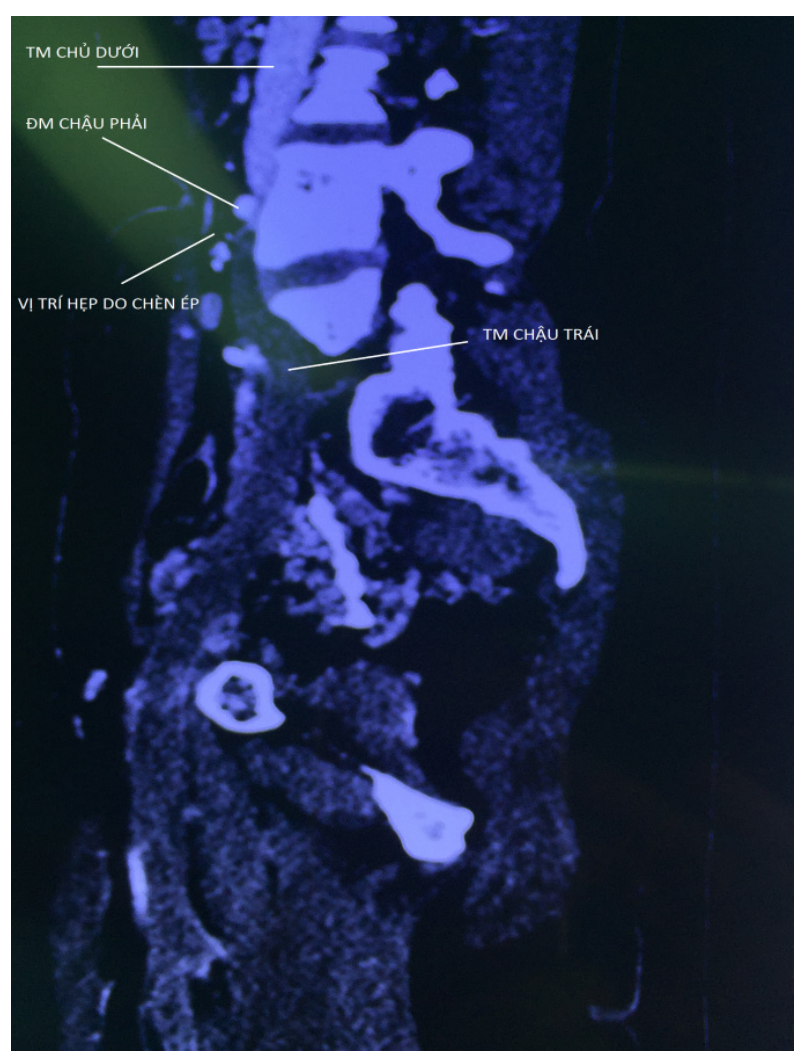

Hình 2. Cắt dọc vị trí chèn ép 


\section{Phẫu thuật - Can thiệp}

Ở nhóm I, tất cả 09 trường hợp May-Thurner đều được phẫu thuật can thiệp mở TM đùi chung lấy huyết khối bằng sonde Fogarty, có hỗ trợ $\mathrm{C}$ Arm. Những trường hợp này, khi luồn Fogarty lên trên khoảng $10-15 \mathrm{~cm}$, đều gặp trở ngại và không thể luồn cao hơn được. Sau khi lấy huyết khối, chụp khảo sát lại dưới C-Arm, chúng tôi ghi nhận vị trí hẹp khít hoặc tắc nghẽn rõ rệt ở vị trí khoảng L4-L5, tương ứng với chỗ hợp lưu hai TM chậu chung. Thuốc cản quang không lan đến được $\mathrm{TM}$ chủ dưới, lan vào nhánh $\mathrm{TM}$ bàng hệ qua TM chậu trong hoặc TM sinh dục.

Chúng tôi chỉ thực hiện được 01 trường hợp luồn guidewire qua được chỗ hẹp, nong bóng và đặt Wallstent, thành công về mặt thủ thuật. Còn lại 08 trường hợp thất bại không thể luồn guidewire qua được chỗ hẹp khít hoặc tắc nghẽn.

Ở nhóm II, can thiệp điều trị lấy huyết khối cho 60 trường hợp, chụp khảo sát trong mổ kết hợp với hình ảnh CT cản quang thì tĩnh mạch, ghi nhận được 37/60 (61,6\%) trường hợp có $\mathrm{HC}$ May-Thurner. Các trường hợp nghi nghờ $\mathrm{HC}$ May - Thurner trước mổ đều được xác định chẩn đoán bằng chụp TM sau khi lấy huyết khối bằng Fogarty tương tự trên. Sau khi xác định tồn thương, chúng tôi tiếp tục can thiệp sửa chữa tổn thương bằng nong bóng - stent, thành công về mặt kỹ thuật là 35/37 (94,6\%).

Huyết khối ở hạ lưu vùng đùi - khoeo được lấy bỏ hoàn toàn bằng cách nắn bóp và vuốt dọc đường đi $\mathrm{TM}$, cho đến khị thấy máu trào ngược về mạnh. Bằng phương pháp này, chúng tôi lấy được huyết khối đoạn đùi khoeo của 7 trường hợp. Có 2 trường hợp nắn bóp không thể lấy hết huyết khối hạ lưu, chúng tôi phải mở TM khoeo dưới gối và luồn guidewire hướng dẫn từ dưới TM khoeo lên trên chỗ mở TM đùi, sau đó đưa sonde Fogarty ngược dòng van xuống dưới, bơm bóng và kéo xuôi chiều van để lấy hết huyết khối TM đùi - khoeo.

Về tai biến - biến chứng, chúng tôi không ghi nhận có thuyên tắc phổi có triệu chứng. Có 1 trường hợp ghi nhận rỉ dịch bạch huyết vết mổ, diễn tiến ổn định sau 2 tuần. Chúng tôi ghi nhận 1 trường hợp chảy máu do vỡ tự phát $\mathrm{TM}$ khoang Retzius, tạo khối máu tụ to vùng tiểu khung, phải phẫu thuật để lấy máu tụ và cầm máu.

\section{Tỷ lệ tái huyết khối sớm}

Ở nhóm I, khảo sát bằng siêu âm Doppler sau mổ 24-48h, chúng tôi ghi nhận chỉ có 1 trường hợp (11\%) TM thông thoáng, còn lại 8 trường hợp $(89 \%)$ có hiện tượng tái huyết khối trong TM. Trong số 8 trường hợp tái phát này có 3 trường hợp (33\%) tái phát huyết khối một phần ở đoạn đùi khoeo, đoạn chậu còn thông thoáng, và 5 trường hợp (56\%) tái huyết khối lại toàn bộ.

Ở nhóm II, tỷ lệ tái huyết khối sớm cải thiện hơn rõ so với nhóm I, là $21,6 \%(8 / 37)$, trong đó có 6 trường hợp tái phát huyết khối toàn bộ, và 2 trường hợp còn huyết khối đùi khoeo, đoạn chậu còn thông thoáng.

\section{Thang điểm VCSS}

Khảo sát bằng thang điểm VCSS ở thời điểm sau 3 tháng điều trị, chúng tôi thu thập được dữ kiện của 8/9 trường hợp HC May-Thurner ( 01 trường hợp không liên lạc được). Điểm VCSS trung bình của 8 trường hợp ở nhóm I sau 3 tháng là 7,625 . Tất cả các trường hợp đều còn phù chân, và phụ thuộc vớ áp lực, mức độ thuyên giảm triệu chứng chưa rõ rệt.

Ở nhóm II, điểm số VCSS cải thiện rõ rệt hơn, trung bình là 5,025. Có 27/37 (73\%) trường hợp người bệnh hết triệu chứng sung phù chân, không phụ thuộc vớ.

\section{BÀN LUẬN}

Năm 1851, tác giả Virchow là người đầu tiên ghi nhận có hiện tượng chèn ép TM chậu bên Trái. Đến năm 1957, dựa trên những quan sát của Virchow trước đó, hai tác giả May và Thurner đã báo cáo về các bất thường giải phẫu học, trong đó TM chậu Trái bị chèn ép bởi ĐM chậu Phải và đốt sống $L 5$, chiếm tỷ lệ từ $22-32 \%$ trong số 430 trường hợp được hai ông tử thiết ${ }^{(10)}$.

Theo số liệu của các tác giả người Nhật, tỷ lệ mắc trong dân số của $\mathrm{HC}$ May-Thurner hiện nay ước tính khoảng $20 \%{ }^{(9)}$. Người ta ghi nhận $\mathrm{HC}$ 
May-Thurner xuất hiện vào khoảng $18-49 \%$ các trường hợp HKTMSCD bên chân Trái ${ }^{(4)}$. Trong loạt bệnh của chúng tôi, tỷ lệ gặp HC MayThurner là $30 \%$. Đa số các tác giả cũng ghi nhận HC May-Thurner thường phát hiện ở nữ giới ở độ tuổi 20-40 tuổi. Kết quả về độ tuổi và giới tính trong các trường hợp $\mathrm{HC}$ May-Thurner của chúng tôi cũng phù hợp với y văn.

Theo May và Thurner, do tác động mạch đập của ĐM chậu Phải đè ép mạn tính lâu ngày lên $\mathrm{TM}$ chậu Trái, sẽ gây ra tình trạng dầy thành $\mathrm{TM}$ khu trú tại chỗ chèn ép (nguyên văn "spur"), do tăng sinh lớp nội mạc và lắng đọng nhiều collagen và elastin. Tiến trình này sẽ tạo nên một chỗ hẹp lòng mạch, diễn tiến dần dần, gây cản trở dòng máu hồi lưu và ứ trệ máu ở ngoại vi. Các rối loạn huyết động này dễ dẫn tới sự tạo lập huyết khối và gây ra HKTMSCD. HC May-Thurner diễn tiến tự nhiên qua 3 giai đoạn: chèn ép không triệu chứng, tạo lạp chố hẹp lòng TM, và tạo lập huyết khối gây tắc nghẽn toàn bọ ${ }^{(5,10)}$. Trong ghi nhận của chúng tôi, tất cả 9 trường hợp đều ở giai đoạn 3 , khi huyết khối tạo lập làm tắc nghẽn toàn bộ TM chậu Trái.

Khảo sát các yếu tố nguy cơ khác, chúng tôi ghi nhận có 2 ca liên quan đến thuốc ngừa thai đường uống. Chúng tôi nghi vấn liệu có tác động cộng hợp của hai yếu tố nguy cơ đồng thời là HC MayThurner và thuốc ngừa thai đường uống dẫn tới HKTMSCD hay không? Tác giả Murphy $\mathrm{EH}$ và Davis $\mathrm{CM}$ cũng có một nghiên cứu tương tự trên 7 trường hợp có $\mathrm{HC}$ May-Thurner kèm theo thuốc ngừa thai đường uống ${ }^{(14)}$, cho rằng các trường hợp dùng thuốc ngừa thai đường uống bị HKTMSCD chân Trái luôn phải khảo sát thêm về HC MayThurner, để tránh bỏ sót yếu tố nguy cơ này.

$\mathrm{HC}$ May-Thurner thường có 02 dạng biểu hiện, một là đợt cấp với HKTMSCD, và hai là mạn tính với biểu hiện của suy tĩnh mạch mạn tính như đau, phù chân thỉnh thoảng, dãn tĩnh mạch, loạn dưỡng da, loét chân... HC MayThurner phải được tầm soát và đặc biệt lưu ý khi triệu chứng xảy ra ở một bên chân Trái ${ }^{(4)}$. Tất cả 46 trường hợp của chúng tôi đều nhập viện trong bệnh cảnh cấp tính có $\mathrm{HKTMSCD}$ và ở một bên chân Trái. Chỉ có 1 trường hợp có kèm theo 01 triệu chứng thuộc nhóm Suy TM mạn tính là dãn TM nông.

Về mặt chẩn đoán bệnh, các phương tiện chẩn đoán hình ảnh học tiện lợi giúp xác định $\mathrm{HC}$ May-Thurner bao gồm CT Venography hoặc MR Venography. Chụp tĩnh mạch cản quang ít được sử dụng hơn do xâm lấn, thường được áp dụng ở các trường hợp phối hợp can thiệp điều trị. Siêu âm Doppler có độ tin cậy thấp trong chẩn đoán $\mathrm{HC}$ này, với độ nhạy chỉ là $47 \%$ cho $\mathrm{TM}$ chậu chung $^{(12,15)}$. CT Venography hiện nay là phương tiện chẩn đoán chính với độ chính xác cao, thuận tiện trong ứng dụng lâm sàng ${ }^{(2,11)}$.

Về mặt điều trị, phác đồ xử trí hiện nay đối với HKTMSCD do HC May-Thurner là can thiệp nội mạch tiêu sợi huyết trực tiếp qua catheter, phối hợp với nong bóng tạo hình và đặt stent chỗ hẹp. Đối với các trường hợp May-Thurner phát hiện ở dạng mạn tính không có huyết khối, nếu không có triệu chứng, sẽ chỉ cần theo dõi. Nếu có triệu chứng mạn tính, sẽ điều trị bằng nong bóng tạo hình và stent ${ }^{(1,2,3,8,13,16)}$. Các tác giả Nhật Bản Igari $K$ và Kudo $T^{(7)}$ cũng báo cáo 8 trường hợp HC May-Thurner được mổ lấy huyết khối và can thiệp đặt stent từ 2009-2011, cho tỷ lệ thông stent sau 16 tháng là $6 / 8$ trường hợp. Một báo cáo khác, các tác giả Halil Bozkaya và Celal Cinar năm $2015^{(6)}$, thực hiện 23 trường hợp can thiệp lấy huyết khối và nong bóng đặt stent trong $\mathrm{HC}$ May-Thurner, cho thấy kết quả tốt, với tỷ lệ tái thông hoàn toàn $\mathrm{TM}$ chậu là $91,3 \%$, tỷ lệ thuyên giảm triệu chứng là $82,6 \%$, tỷ lệ thông thoáng stent sau 1 năm là 90,4\%, tái hẹp 2 trường hợp.

Trong nhóm khảo sát của chúng tôi, do điều kiện cơ sở trang thiết bị chưa đầy đủ, nên chúng tôi chưa thực hiện được việc lấy huyết khối bằng can thiệp nội mạch tiêu sợi huyết trực tiếp qua catheter. Chúng tôi thực hiện việc lấy huyết khối bằng phương pháp phẫu thuật kinh điển với sonde Fogarty. Tuy nhiên trong giai đoạn đầu, ở nhóm I, kết quả tái huyết khối sớm của chúng tôi còn cao, do giới hạn trong việc khảo sát và xử lý thương tổn hẹp tắc trong HC May-Thurner. Chính vì vậy, hiệu quả điều trị của 9 trường hợp này 
không được tốt, đa số bệnh nhân còn sưng chân và phụ thuộc vớ áp lực nhiều. Chính vì vậy, hướng nghiên cứu tiếp theo của chúng tôi ở nhóm II, sau khi đã lấy huyết khối là phải tái thông lại chỗ hẹp hoặc tắc tại TM chậu chung bị chèn ép, hoặc bằng nong bóng đặt stent, đã cho kết quả khả quan hơn rõ rệt, khi so sánh bằng tỷ lệ tái huyết khối và mức độ cải thiện lâm sàng theo thang điểm VCSS.

\section{KẾT LUẬN}

HKTMSCD do HC May-Thurner là bệnh cảnh thường gặp trên lâm sàng. Cần lưu ý hướng đến chẩn đoán này khi người bệnh có biểu hiện sưng phù 1 bên chân Trái. Phương tiện chẩn đoán xác định dựa vào hình ảnh học với vai trò của chụp CT Venography, xác định chắc chắn bằng chụp TM cản quang trong mổ. Điều trị theo phác đồ hiện nay là lấy huyết khối và sửa chữa thương tổn giải phẫu bằng nong bóng và stent.

\section{TÀI LIỆU THAM KHẢO}

1. Anthony Corometa, Jorge L. Martinez (2009). Catheter-directed thrombolysis for treatment of acute deep venous thrombosis. Handbook of venous disorders, $3^{\text {rd }}$, pp. 239.

2. Baron HC, Shams J, Wayne M. (2000). Iliac vein compression syndrome: a new method of treatment. Am Surg, pp. 653.

3. Bo Eklof, Robert McLafferty (2009). Surgical thrombectomy and percutaneous mechanical thrombectomy for treatment of acute iliofemoral deep venous thrombosis. Handbook of venous disorders, $3^{\text {rd }}$, pp. 255.

4. Donatella N, Marcello BU (2014). What the young physician should know about May-Thurner syndrome. Translational Medicine, pp. 1219.

5. Fowkes FJ, Price JF (2003). Incidence of diagnosed deep venous thrombosis in the general population: systematic review. Eur Vasc Endovasc Surg, pp. 25.

6. Halil Bozkaya, Celal Cinar (2015). Endovascular Treatment of Iliac Vein Compression (MayThurner) Syndrome: Angioplasty and Stenting with or without Manual Aspiration
Thrombectomy and Catheter-Directed Thrombolysis. Ann Vasc Dis, pp. 21-28.

7. Igai K, Kudo T (2014). Surgical thrombectomy and simultaneous stenting for deep venous thrombosis caused by iliac vein compression syndrome (May-Thurner syndrome). Ann Thorac Cardiovasc Surg, pp. 995-1000.

8. Kasirajan K, Gray B, Ouriel K. (2001). Percutaneous angiojet thrombectomy in the management of extensive deep vein thrombosis. J Vasc Interv Radiol, pp. 179-185.

9. Kibbe MR, Ujiki M, Goodwin AL, Eskandari M, Yao J, Matsumura J (2004). Iliac vein compression in an asymptomatic patient population. J Vasc Surg, pp. 937-943

10. May R, Thurner J (1957). The cause of the predominately sinistral occurrence of thrombosis of the pelvic veins. Angiology, pp. 419-427.

11. McDermott S, Oliveira G, Ergül E, Brazeau N, Wicky S, Oklu R. (2013). May-Thurner syndrome: can it be diagnosed by a single MR venography study?. Diagn Interv Radiol, pp. 44.

12. Messina LM, Sarpa MS, Smith MA, Greenfield LJ (1993). Clinical significance of routine imaging of iliac and calf veins by color flow duplex scanning in patients suspected of having acute lower extremity deep venous thrombosis. Surgery, pp. 921

13. Michael B. Streiff, Giancarlo Agnelli (2016). Guidance for the treatment of deep vein thrombosis and pulmonary embolism. J Thromb Thrombolysis, pp. 32-67.

14. Murphy EH, Davis CM (2009). Symptomatic ileofemoral DVT after onset of oral contraceptive use in women with previously undiagnosed May-Thurner syndrome. J Vasc Surg, pp. 697-703.

15. Oguzkurt L, Ozkan U, Tercan F, Koc Z (2007). Ultrasonographic diagnosis of iliac vein compression (May-Thurner) syndrome. Diag Interv Radiol, pp. 152-155.

16. Thomas W.Wakefield (2009). Treatment algorithm for acute deep venous thrombosis: current guidelines. Handbook of venous disorders, $3^{\text {rd }} 2009$, pp. 265. 